Original article

\title{
Prevalence of diarrhoea among under five children in India and its contextual determinants: A geo-spatial analysis
}

\author{
Koustav Ghosh ${ }^{\mathrm{a}, \mathrm{c}, *}$, Atreyee Sinha Chakraborty ${ }^{\mathrm{a}}$, Mithun Mog ${ }^{\mathrm{b}}$ \\ ${ }^{\text {a }}$ Gokhale Institute of Politics and Economics, Pune, Maharashtra, India \\ ${ }^{\mathrm{b}}$ National Institute of Technology, Agartala, Tripura, India \\ ${ }^{\mathrm{c}}$ Population Research Centre (PRC), Vadodara, Gujarat, India
}

\section{A R T I C L E I N F O}

\section{Keywords:}

Diarrhoea

Spatial analysis

Malnutrition

Hot-spot

Auto-correlation

Morbidity

India

\begin{abstract}
A B S T R A C T
Background: Diarrheal diseases which is one of the leading reason behind global mortality and morbidity is more threatening for infants and young children. Childhood diarrhoea is becoming increasingly prevalent disease in developing countries like India. Moreover, it is a major cause of malnutrition that contributes towards third major cause of under 5 mortalities. This has raised a serious concern in the domain of public health.

Objectives: The present study attempts to identify the spatial prevalence and clustering of diarrhoea in India based on National Family and Heath Survey (NFHS-4, 2015-16) and also tries to identify the association of prevalence of diarrheal disease among under 5 children with socio-economic factors.

Methods: The study applies spatial analysis software i.e ArcGIS 10.8 and GeoDa 1.18 including Moran's index and logistics regression to show the spatial prevalence and auto-correlation of diarrhoea among neighbourhood districts and their contextual determinants.

Findings: The study finds a total of 71 districts belong to the hot spot area are mostly from central and eastern costal part of India. Analysis of socio-economic determinants show prevalence of diarrhoea among under 5 children is higher in rural areas, among children not staying in Pacca house, living with unimproved sanitation facilities, belonging to under privileged community (highest among OBC followed by SC/STs), children of younger mothers ( $<25$ years) and "poor' households considering the wealth index.

Conclusion: The study recommends to target hot-spot districts with high prevalence of diarrhoea and policy level interventions like improved sanitation to reduce the risk of childhood diarrhoea.
\end{abstract}

\section{Introduction}

Diarrhoea is one the leading reasons of under-five child mortality and morbidity across globe. These diseases can be caused by bacteria, viruses and protozoan parasites infection especially among young and adult children. ${ }^{1,2}$ According to the latest report of World Health Organisation, nearly $8 \%$ of under five children death is due to diarrhoea disease. ${ }^{3}$ This indicates an alarming situation worldwide. The latest report of United Nations International Children's Emergency Fund (UNICEF) revealed that deaths among under five children are mostly are caused by malnourishment (45\%), Pneumonia (15\%) diarrhoea (8\%), malaria (5\%) and others (9\%). ${ }^{4}$ Moreover, diarrhoea disease is the major cause of malnutrition that contributes towards third major cause of under 5 mortality specially in the developing countries. ${ }^{4,5}$ Further, globally 1.7 billion children are affected by diarrhoea out of that more than half millions of children die every year. Precisely, diarrhoea is more prevalent, when a child is in second year of his life. ${ }^{4,6}$

In the developing countries, on an average three times in a year an under 5 child suffer from diarrhoea. ${ }^{7,8}$ Five countries India, Nigeria, Congo, Pakistan and China together contribute for half of the diarrhoea death among children (4.249 Million) in 2008.,

The National Family Health Survey shows that the prevalence of childhood diarrhoea has increased from 9\% to 9.2\% from 2016 to 2020 in India. It is the third most common responsible disease for under five mortality. ${ }^{10}$ Profound studies have revealed that under five mortality persists due to diarrhoea in India. It is, thus, clear that this disease is a major public health issue in India. A study shows that under-five mortality and infant mortality (IMR) has been reduced to $50 \%$ and $41 \%$ in 2016 from 74\% and 57\% in 2005. ${ }^{11}$ Furthermore, Kamath et al. (2018), have mentioned that among the states Uttar Pradesh and Assam have

\footnotetext{
* Corresponding author. Gokhale Institute of Politics and Economics, Pune, India.

E-mail addresses: koustav2020@gmail.com, koustav.ghosh@gipe.ac.in (K. Ghosh), sinhaatreyee@gmail.com (A.S. Chakraborty), mi2un90@gmail.com (M. Mog).
} 
shown more prevalence of childhood diarrhoea deaths than rest of the states of India. ${ }^{12}$ Some more studies have shown mother's age, age of child, social class, religion, residence and wealth index have influence on childhood diarrhoeal cases in India. ${ }^{13,14}$

Diarrhoea disease among children has become crucial health concerns in India. In spite of having different interventions and schemes to control, diarrhoea death among under five children in India is still alarming. Further, studies related to these issues are mostly region specific, and are less focussed on associated risk factors using large scale data. ${ }^{15-17}$ Therefore, present study aims to show the prevalence of diarrhoea disease among under 5 children across districts of India using widely accepted nationally representative data and tries to find out the most responsible factors behind the occurrence of diarrhoea among children. We have used spatial tools to show the spatial prevalence and clustering of diarrhoea by incorporating multiple linked risk factors which has not been reported till date. This study findings would give a widespread knowledge about spatial prevalence and also it may help to identify the hot-spot districts of higher prevalence states of diarrhoea disease in India and districts with $<0.05 \%$ significance level of map. Further, result of mapping might help to formulate preventive strategies for reducing child deaths due to diarrhoea disease in India. Finding out the socio-economic determinants of occurrence might also help in designing the intervention strategies.

\section{Materials and methods}

\subsection{Data source}

The study uses National Family Health Survey-IV (NFHS-4) data of India, 2015-16. This survey had covered 35 states/UTs including 640 districts in India (IIPS \& ICF, 2017). This national level large-scale survey conducted under the supervision of the Ministry of Health \& Family Welfare (MoHFW), Government of India and International Institute for Population Sciences (IIPS), Mumbai, was the nodal agency for that survey. Total 601,509 households were interviewed along with a response rate of $98 \%$ (over $90 \%$ in the case of every state and union territory), and $97 \%$ for eligible women who are in the age group of $15-49$ and $92 \%$ of men aged $15-54$.

The Information on childhood diarrhoea was given by the mother of the child/children under 5 years from the sampled household. The question was asked that whether her child/children had suffered from diarrhoeal diseases before last two weeks of the survey. However, to mention here, an accuracy of these replies depends on the mother's recall and her knowledge on diarrhoea disease. Two weeks recall was thought to be small enough to minimize the recall bias. Also, the illnesses reported are based on mother's perception and without spot validation by medical person.

\subsection{Methodology}

To understand the geographical variation and spatial clustering of diarrhoea in the districts of India, the study uses spatial analysis software ArcGIS 10.8 and GeoDa 1.18. To determine the existence of clustering, spatial heterogeneity and spatial auto-correlation in prevalence of childhood diarrhoea, Exploratory Spatial Data Analysis (ESDA) has been attempted. ${ }^{18}$ Geographical Information System (GIS) and spatial statistical technique based on ESDA are useful in describing and representing spatial distribution, detecting hot-spot and cold-spot areas and suggesting spatial regimes or other forms of spatial heterogeneity. ${ }^{18,19}$

\subsection{Spatial analysis}

To analyse hot-spot in spatial tools the scale measure is important to specify the distance value (Parvin et al., 2020) of the map. For that, spatial weight matrix (W) is essential for computation of the spatial autocorrelation among districts of study area. To construct the matrix, we need to define neighbourhood by assigning spatially contiguous weights (queen's weight) that include all common points. To show the spatial autocorrelation among the districts, we use Moran's I and Local Indicators of Spatial Autocorrelation (LISA) to measure the extent of autocorrelation among the neighbourhood districts. Moran's I helps to understand the intensity of clustering (Z-score) with increasing the distance. The output of z-score is used to determine the intensity of clustering. Usually, z-score indicates the rate of clustering that gets intensified with increasing distance. But at a certain distance the when $\mathrm{z}$ score becomes peak it reveals distances where clustering are most prominent. ${ }^{20}$ LISA statistics has been used to detect the hot-spot area across the districts considering the percentage of children who suffered from diarrhoea in the study area. ${ }^{12}$ The LISA values consent the computation of its similarity with its neighbour districts and also test the level of significance ( $p$ values) for each locations. Moreover, LISA map portrays the results of five scenarios-cluster with high values (high-high or hot spot), cluster with low values (low-low or cold spot), outlier in which a high value which is surrounded by a low value (high-low), outliers in which a low value is surrounded by a high value (low-high) and no significant local autocorrelation. Additionally, we have used Logistic regression model to know most responsible factors of diarrhoea and contextual correlates in STATA-14. In that model we used explanatory variables and have fitted step wise logistics regression model by including various predictors (i.e., Environmental, Socio-economic, and Children) in following manner. ${ }^{21}$

Model 1: We have included only environmental characteristics-types of house, source of drinking water, sanitation facility, and month of interview. Model 2: Along with the environmental characteristics we included socio-economic variable in Model 2, i,e place of residence, social-groups, religion, mother's education, mother's age, and wealth index are included under the Socio-economic variable. Model 3: In the final model we have included all three categories of variables: environmental (as described in model 1), socio-economic (as described in model 2) and children characteristics related variables which includesex of the child, age of the child, birth order of the child, stunting, and religion.

\section{Results}

3.1. Prevalence of diarrhoea with geographical variation in India, 2015-2016

The geographical variation of diarrhoea among children age underfives years at the state/UTs in India (2015-16) is represented in Table 1. At the national level, the prevalence of diarrhoea has been reported of $9.2 \%$. About $9.5 \%$ of male children and $8.9 \%$ of female children are living with diarrhoea disease. Eight states/UTs have shown more than the national average of diarrhoea prevalence. The prevalence of diarrhoea is high in Uttarakhand (17.1\%) followed by Uttar Pradesh (15\%), Puducherry (11.3\%), and Meghalaya (10.6\%). On the contrary, Sikkim (1.8\%), Assam (2.9\%), and Kerala (3.4\%) have reported of having lower prevalence of diarrhoea disease among $0-5$ aged children in India. Among male child the prevalence of diarrhoea varies from $1.8 \%$ (Sikkim) to $17.5 \%$ (Uttarakhand). Contrastingly, among female the range is from $0.5 \%$ (Sikkim) to $16.5 \%$ (Uttarakhand).

$35 \%$ of districts (222 out of 640 ) in India have reported the prevalence of diarrhoea by more than national average (9.2\%). For $19 \%(120$ districts) the prevalence lies between $7 \%$ to $9.2 \%$ and the remaining $47 \%$ districts have reported the prevalence under $7 \%$ in 2016 . Ramban (44.8\%) and Kishtwar (43.8\%) districts from Jammu \& Kashmir have shown the highest prevalence of diarrhoea and the South District ( $0 \%)$ of Sikkim and Udalguri (0.6\%) of Assam reported low diarrhoea prevalence. The high prevalence districts are from central, south-west, north east and Northern part of India, mostly from Uttar Pradesh, Madhya Pradesh, Bihar, Uttarakhand, Gujarat, Maharashtra, and Jharkhand states of India. Fig. 1 illustrated the spatial prevalence of diarrhoea in 
Table 1

Prevalence of diarrhoea among $0-5$ aged children in India and states/UTs, 2015-16.

\begin{tabular}{|c|c|c|c|c|}
\hline \multirow[t]{2}{*}{ State/UTs } & \multicolumn{3}{|c|}{$\begin{array}{l}\text { Diarrhoea Prevalence (in } \\
\text { percentage) }\end{array}$} & \multirow[t]{2}{*}{ Sample Size } \\
\hline & Male & Female & Total & \\
\hline Sikkim & 2.9 & 0.5 & 1.8 & 975 \\
\hline Assam & 3.1 & 2.8 & 2.9 & 9766 \\
\hline Kerala & 3.5 & 3.2 & 3.4 & 2443 \\
\hline Goa & 3.4 & 4.1 & 3.8 & 410 \\
\hline Daman \& Diu & 3.7 & 3.9 & 3.8 & 395 \\
\hline Dadra \& Nagar Haveli & 5.9 & 2.5 & 4.2 & 311 \\
\hline Karnataka & 4.7 & 4.2 & 4.5 & 7533 \\
\hline Chandigarh & 3.9 & 5.3 & 4.6 & 187 \\
\hline Tripura & 5.6 & 4.2 & 4.9 & 1291 \\
\hline Nagaland & 5.1 & 5.1 & 5.1 & 4410 \\
\hline Andaman \& Nicobar Islands & 5.0 & 5.7 & 5.3 & 637 \\
\hline Manipur & 6.0 & 5.6 & 5.8 & 5477 \\
\hline West Bengal & 5.9 & 5.8 & 5.9 & 5160 \\
\hline Lakshadweep & 6.7 & 5.9 & 6.3 & 300 \\
\hline Andhra Pradesh & 6.7 & 6.5 & 6.6 & 3013 \\
\hline Arunachal Pradesh & 6.6 & 6.6 & 6.6 & 4772 \\
\hline Punjab & 6.7 & 6.5 & 6.6 & 5037 \\
\hline Himachal Pradesh & 6.7 & 6.6 & 6.7 & 2808 \\
\hline Jharkhand & 7.3 & 6.5 & 6.9 & 11,625 \\
\hline Rajasthan & 7.6 & 7.1 & 7.4 & 16,065 \\
\hline Jammu \& Kashmir & 7.5 & 7.5 & 7.5 & 7916 \\
\hline Mizoram & 7.4 & 7.8 & 7.6 & 4662 \\
\hline Haryana & 7.4 & 8.1 & 7.7 & 7568 \\
\hline Tamil Nadu & 7.7 & 8.2 & 8.0 & 7716 \\
\hline Telangana & 8.5 & 7.9 & 8.2 & 2345 \\
\hline Gujarat & 8.7 & 8.1 & 8.4 & 7399 \\
\hline Maharashtra & 8.7 & 8.4 & 8.5 & 9146 \\
\hline Chhattisgarh & 9.1 & 9.2 & 9.1 & 8733 \\
\hline Madhya Pradesh & 9.9 & 9.1 & 9.5 & 23,210 \\
\hline NCT Of Delhi & 12.6 & 6.2 & 9.7 & 1514 \\
\hline Odisha & 10.0 & 9.7 & 9.8 & 10,575 \\
\hline Bihar & 10.7 & 10.2 & 10.4 & 24,064 \\
\hline Meghalaya & 9.8 & 11.3 & 10.6 & 4244 \\
\hline Puducherry & 14.6 & 7.4 & 11.3 & 1061 \\
\hline Uttar Pradesh & 15.6 & 14.3 & 15.0 & 38,852 \\
\hline Uttarakhand & 17.5 & 16.5 & 17.1 & 5561 \\
\hline India & 9.5 & 8.9 & 9.2 & $2,47,181$ \\
\hline
\end{tabular}

Source: National Family Health Survey (NFHS)-4, 2015-16

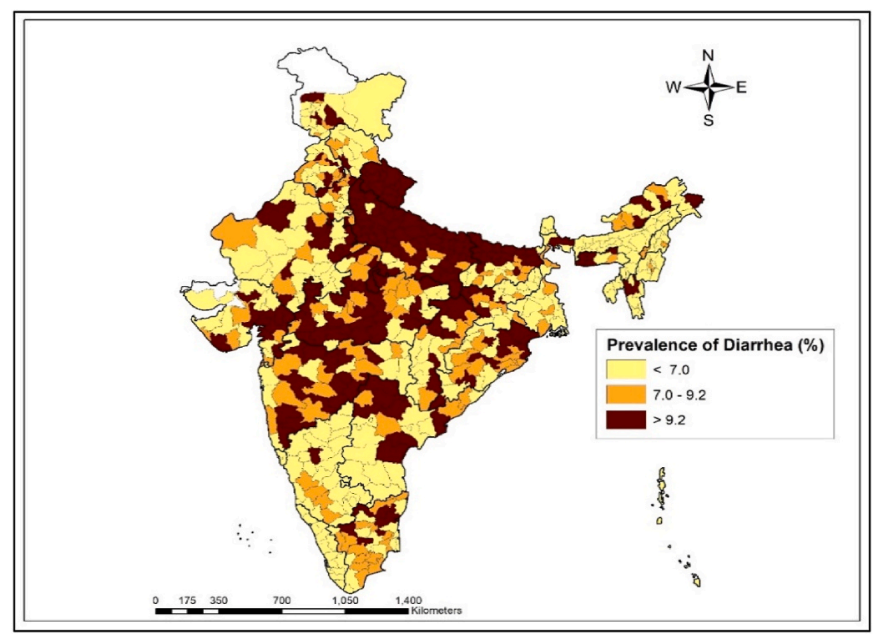

Fig. 1. Spatial prevalence of diarrhoea among children aged $0-5$ years in districts of India, 2015-16. the districts (total 640) for India.

\subsection{Spatial clustering of diarrhoea in districts of India, 2015-2016}

Moran's Index statistics of spatial autocorrelation shows the prevalence of diarrhoea in the districts of India as a cluster (Moran's Index is 0.3746 ) and the results are also highly significant ( $p$ value $<0.001$ ) (Fig. 2). Based on this result, The LISA map has identified the probable hot-spot area of childhood diarrhoea prevalence at the district level in India (depicted in Figure- 3). In Fig. 3 highlights in map A shows clustering prevalence of diarrhoea, and map B depicts the significant levels of clustering. The area of hot spots (high to high) area shown in red colour, the districts with a higher prevalence of diarrhoea are surrounded by neighbouring districts with greater levels of diarrhoea. Contrarily, cold spots (low to low) shown in blue colour are those districts with lower levels of diarrhoea prevalence and also have similar neighbourhoods. A total of 71 districts fall into the hot-spot area which are mostly from Uttar Pradesh and Odisha states, whereas, 83 districts are showing cold-spot areas from the south, north, east, and north-east parts of India. Level of Significant map represents around 183 districts have reported in cluster with $\geq 5 \%$ significance level.

\subsection{Prevalence and association of diarrhoea disease with environmental,} socio-economic, and child characteristics as background variables, 2015-2016

Descriptive statistics of environmental, socio-economic, and child characteristics from the data is presented in Table 2 . The analysis of data shows that out of 2, 47,181 sample of children 22,500 (9.2\%) children had suffered from diarrhoea disease within two weeks before the survey. The prevalence of diarrhoea is found to be higher among households who are using improved drinking water $(9.22 \%)$ and unimproved (9.79\%) sanitation facilities. Childhood diarrhoea is highly prevalent in people living with kuccha (11.67) house as compared to other type of houses. Prevalence of diarrhoea is high in rural (9.57\%) residence as compared to urban counterpart. In terms of social groups, Other Backward class (OBC) (9.62\%) have reported high cases of diarrhoea followed by SC/ST $(9.12 \%)$ and others $(8.81 \%)$. Similarly, from religion point of view, Muslim children (9.92\%) have reported a higher prevalence of diarrhoea as compared to other religious groups. The prevalence of childhood diarrhoea is high when mother's age is less than 25 years $(10.67 \%)$, and have primary education $(10.02 \%)$ and who are working $(9.72 \%)$. In the case of the household wealth index, poor $(9.87 \%)$

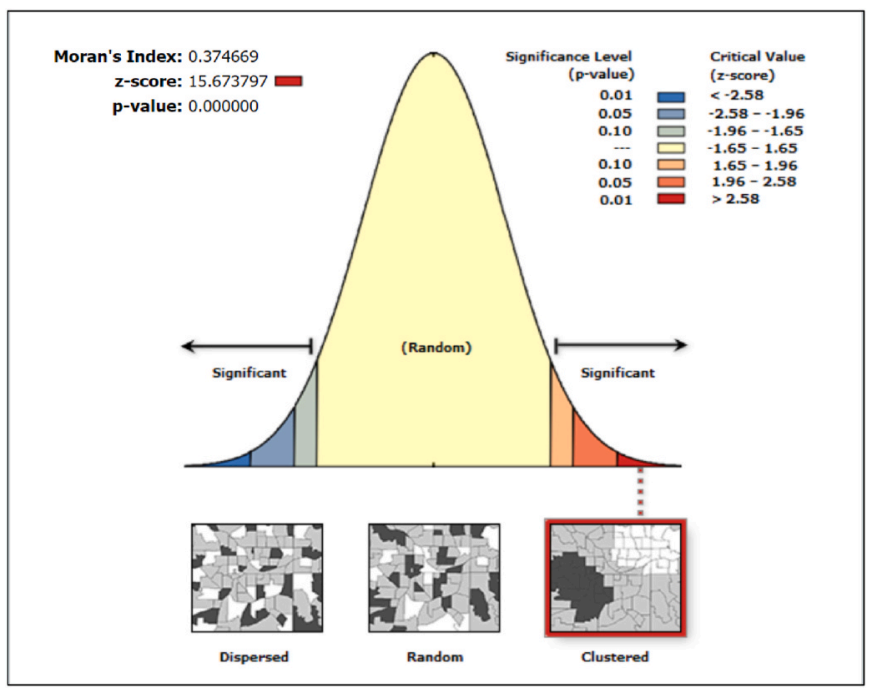

Fig. 2. Graphical presentation of the result of spatial autocorrelation of diarrhoea prevalence among children in districts of India, 2015-16. 


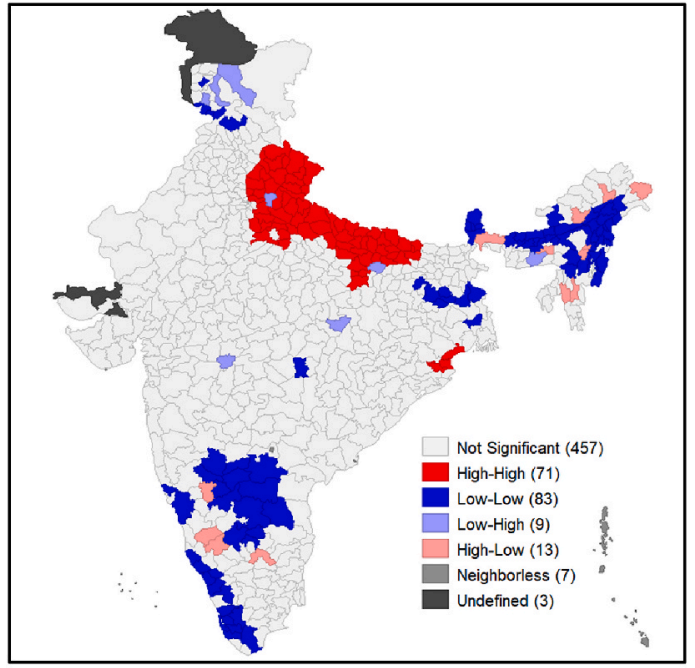

A. LISA cluster map

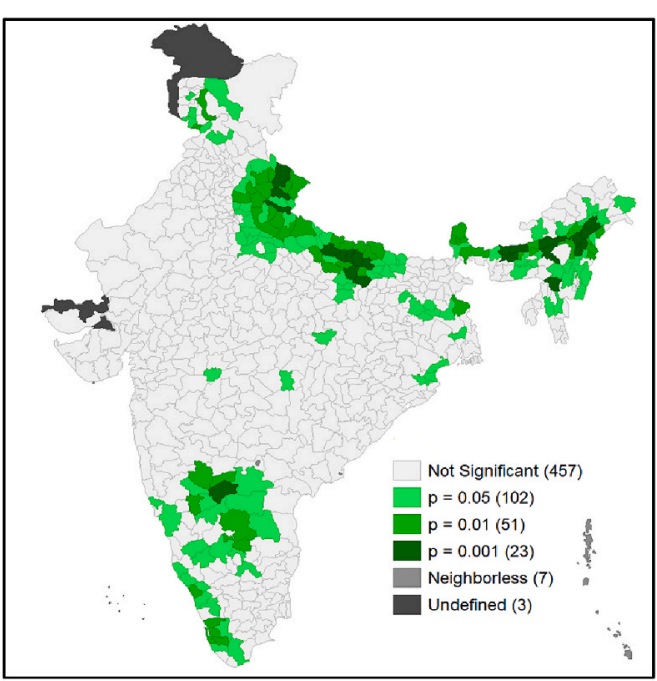

B. LISA significance map

Fig. 3. LISA cluster map and significance map for diarrhoea prevalence among children in districts of India, 2015-16.

household's children have shown higher cases of diarrhoea disease against middle (9.27\%) and rich (8.19\%) household. Further, children aged less than 11 years $(14.01 \%)$ tends to suffer from diarrhoea more compared to other age groups of children. Boys (9.47\%), children of three and more birth order (10.08\%) and stunted (9.51\%) have shown more vulnerability against their counterparts. Moreover, region specific study result depicts that diarrhoea cases are higher in the central (13.6\%) region as compare to other geographical regions of India (see Table 2).

\subsection{Childhood diarrhoea and its contextual determinants}

Results of logistic regression analysis shows (see Table 3) that type of house, source of drinking Water, type of sanitation facility, season, religious groups, mother's education, mother's occupation, mother's age, wealth index, sex of a child, age of a child and regions of India have found to be significant with childhood diarrhoea. Among environmental factors it has found the odds of children who are living in the pacca house (OR $=0.73, \mathrm{CI}=0.62,0.86$ ) are less likely to suffer from diarrhoea disease as compared to those live in kachha house in model-1 while controlling the effects of Socio-economic (Model-2), child characteristics and others variable (Model-3). Household living with unimproved drinking water are less likely to suffer from diarrhoea as compare to improved water in all three models. As per NFHS-4 2015-16, 89\% of households are using improved water facility so the reason behind the occurrence of maximum diarrhoea cases from the household using improve drinking water can be a result of a class biasness. Children with unimproved sanitation facility have 1.07 times higher chances of suffering from diarrhoea compared to household using improved sanitation facility.

Among socio-economic variables, the odds of children suffering from diarrhoea is more among Muslim religion and significantly high in all model and less in the other religious group, though when other variables are included in model 3 it becomes insignificant. Rural residence indicates 1.04 times higher chances of suffering from diarrhoea compared to urban residence in model 2 , when Children and Others variable is not taken into consideration. Diarrhoea among children of secondary and higher educated mother and working mother are noticeably high. With increasing age of mother, the probability of suffering from diarrhoea has been reduced both in the model $2 \& 3$ but when child and other variables are included in model 3 mothers greater than 35 years of age does not show any significant relationship. Children of rich quantile household are markedly less likely to experience diarrhoea (in model 3) compared to poor household. Model 3 shows a number of child related factors significantly associated with diarrhoea. The odds $(\mathrm{OR}=0.87, \mathrm{CI}=0.80$, 0.93) of children suffering from diarrhoea among female is less compared to their male counterpart. Children from central region of India are 1.29 times more likely to suffer from diarrhoea against north region in model 3 where, east, north-east and south region are less likely to suffer diarrhoea as compared to north region (Table 3).

\section{Discussions and conclusions}

Diarrhoea is one of the leading killer diseases among underfive years children so it is an important public health problem in India. India already sets her goals to achieve the SDGs target to reduce under-five child mortality by 25 in 2030 (WHO \& SDGs). To achieve Millennium development Goal-4 (MDG), and reduce child mortality the government of India innovated various program and schemes like the child survival and safe motherhood program (1992), target-free approach (1996), reproductive and child health program (RCH) in 1997 and 2005, national rural/urban health mission between 2005 and 2012, national health mission (NHM) in 2013 to-date, program related to immunization and prevent diarrheal disease and acute respiratory infection (ARI). As a result, under-five mortality (U-5MR) reduced down 55 to 29 per 1000 live births between 2011 to $2015 .^{10,11,38}$ To prevent under-five mortality and to achieve the various targets (including SDGs and MDG), special attention needs to be put on the most prevalent diseases among under-five children including diarrhoea.

In India $9.2 \%$ of under 5 children suffer from diarrhoea disease. $\left(\right.$ NFHS-4) ${ }^{14}$ The present study reveals that remarkable geographical variation (lowest in Sikkim, highest in Uttarakhand) in the risk of childhood diarrhoea disease of all districts of India. The study findings highlight that the higher prevalence of diarrhoea is in the central and eastern part of India and lowest is in north-east and southern part of India. Around 35\% districts are having more than the national level diarrhoeal diseases. Districts in the central part of India have been identified as highest diarrhoea prevalence zone.

The present study shows that the medium to high level of clustering of diarrhoea in the districts with 0.38 Moran's Index, which means autocorrelation exists between neighbourhood districts. ${ }^{12}$ Similar findings were identified by Kamath et al. (2018). Total 71 districts have been identified as a hot-spot area from central and eastern Part of India and 183 Districts have shown more than 95\% level significance.

The present study finds occurrence of childhood diarrhoea is correlated with the characteristics and infrastructural facilities of the house. 
Table 2

Overall preview prevalence of diarrhoea and relationship of independent categorical variables of children aged 0-5 in India, 2015-16.

\begin{tabular}{|c|c|c|}
\hline Predictors & N (\%) of Diarrhoea & Chi-square-P value \\
\hline \multicolumn{3}{|l|}{ Prevalence of Diarrhoea } \\
\hline No & $224,681(90.81)$ & \\
\hline Yes & $22,500(9.19)$ & \\
\hline \multicolumn{3}{|l|}{ Environmental Characteristics } \\
\hline \multicolumn{3}{|l|}{ Type of house $^{a}$} \\
\hline Kaccha & 170 (11.67) & \\
\hline Semi-pucca & 9037 (10.29) & \\
\hline Pucca & $11,878(8.36)$ & $<0.001$ \\
\hline \multicolumn{3}{|l|}{ Source of drinking Water ${ }^{\mathrm{b}}$} \\
\hline Improved & $18,807(9.22)$ & \\
\hline Unimproved & $2278(8.04)$ & $<0.001$ \\
\hline \multicolumn{3}{|l|}{ Sanitation facility ${ }^{c}$} \\
\hline Improved & $10,090(8.41)$ & \\
\hline Unimproved & $10,995(9.79)$ & $<0.001$ \\
\hline \multicolumn{3}{|l|}{ Month of Interview ${ }^{\mathrm{d}}$} \\
\hline Rainy Session & $10,420(8.70)$ & \\
\hline Others & $12,080(9.66)$ & $<0.001$ \\
\hline \multicolumn{3}{|l|}{ Socio-economic Characteristics } \\
\hline \multicolumn{3}{|l|}{ Place of residence } \\
\hline Urban & $5169(8.24)$ & \\
\hline Rural & $17,331(9.57)$ & $<0.001$ \\
\hline \multicolumn{3}{|l|}{ Caste $^{\mathrm{e}}$} \\
\hline Scheduled Caste/Scheduled Tribe & $8156(9.12)$ & \\
\hline Other Backward Class & $9425(9.62)$ & \\
\hline Others & $4055(8.81)$ & $<0.001$ \\
\hline \multicolumn{3}{|l|}{ Religion ${ }^{\mathrm{f}}$} \\
\hline Hindu & $16,406(9.15)$ & \\
\hline Muslim & 4115 (9.92) & \\
\hline Others & $1979(7.34)$ & $<0.001$ \\
\hline \multicolumn{3}{|l|}{ Mother's Education } \\
\hline No education & $6959(9.46)$ & \\
\hline Primary & $3488(10.02)$ & \\
\hline Secondary \& Higher & $12,053(8.48)$ & $<0.001$ \\
\hline \multicolumn{3}{|l|}{ Mother's Occupation } \\
\hline Not working & $3048(9.24)$ & \\
\hline Working & $966(9.72)$ & 0.14 \\
\hline \multicolumn{3}{|l|}{ Mothers Age } \\
\hline 15-24 Years & 8568 (10.67) & \\
\hline 25-34 Years & $12,093(8.46)$ & \\
\hline 35-49 Years & $1836(7.98)$ & $<0.001$ \\
\hline \multicolumn{3}{|l|}{ Wealth Index } \\
\hline Poor & $11,457(9.87)$ & \\
\hline Middle & $4538(9.27)$ & \\
\hline Reach & $6505(8.19)$ & $<0.001$ \\
\hline Children Characteristics & & \\
\hline Sex of Child & & \\
\hline Girl & $10,397(8.88)$ & \\
\hline Boy & $12,103(9.47)$ & $<0.001$ \\
\hline Age of Child (In Months) & & \\
\hline 0-11 months & $6472(14.01)$ & \\
\hline $12-35$ months & $10,621(10.97)$ & \\
\hline $36-59$ months & $5246(5.25)$ & $<0.001$ \\
\hline Birth order of Child & & \\
\hline 1st Birth order & $8034(8.71)$ & \\
\hline 2nd Birth order & 6946 (8.97) & \\
\hline 3 and Above Birth order & $7520(10.08)$ & $<0.001$ \\
\hline A z-score of height for age (Stunti & & \\
\hline Normal & $12,772(9.26)$ & \\
\hline Stunted & $8009(9.51)$ & 0.57 \\
\hline Others Characteristics & & \\
\hline Regions & & \\
\hline North & $4223(8.10)$ & \\
\hline East & $4393(8.73)$ & \\
\hline North-East & $1953(4.16)$ & \\
\hline Central & $8824(13.06)$ & \\
\hline West & $1534(8.45)$ & \\
\hline South & 1573 (6.49) & $<0.001$ \\
\hline
\end{tabular}

a Type of house: Kaccha House: Houses made from mud, thatch, or other lowquality materials. Semi pucca House: houses that use partly low-quality and partly high-quality materials. Pucca House: houses made with high quality materials throughout, including the floor, roof, and exterior walls, are called pucca houses. b Source of drinking Water: Improved source of drinking water: Include piped water, public taps, standpipes, tube wells, boreholes, protected dug wells and springs, rainwater, and community reverse osmosis (RO) plants. Unimproved source of drinking water: Unprotected dug well, Unprotected spring, Tanker truck/cart with small tank, Surface water, Bottled water (The quality of bottled water is not known, households using bottled water are classified as using an unimproved source in accordance with the practice of the WHO-UNICEF Joint Monitoring Programme for Water Supply and Sanitation).

c Sanitation facility: Improved sanitation facility: Include any non-shared sanitation of the following types: flush/pour flush sanitations to piped sewer systems, septic tanks, and pit latrines; ventilated improved pit (VIP)/biogas latrines; pit latrines with slabs; and twin pit/composting sanitations. Unimproved sanitation facility: Flush/pour flush not to sewer/septic tank/pit latrine, Pit latrine without slab/open pit, and Dry sanitation.

d Month of Interview: Rainy Session: It include May, June, July and August month. Others: January, February, March, April, September, October, November and December.

e Stunted: Children whose height-for-age Z-score is below minus two standard deviations $(-2 \mathrm{SD})$ from the median of the reference population are considered short for their age (stunted), or chronically undernourished and else are considered as a Normal.

f Caste: The Indian constitution (1949) created broad categories of under privileged groups in the republic of India that were to be the object of special administrative and welfare efforts. These categories were named, though not clearly defined. SC/ST: Two groups of historically disadvantaged people recognised in constitution of India and are known as depressed classes. OBC: Other socially and educationally disadvantaged classes not included in SC/ST.

g Religion: Others: it includes Christians, Sikhs and Buddhists/Neo-Buddhists, Jain and others religion.

Source: National Family Health Survey (NFHS)-4, 2015-16, N: number of cases; $\%$ : prevalence of diarrhoea

Children living in pucca house have experienced it lesser. The finding is quite similar to some of the recent studies. ${ }^{12,22-27}$ Moreover, household having improved sanitation facility also have the lesser risk of diarrhoea disease among under five children (resembles the result $s$ of the study by Kumar \& Das, 2014; Kumar \& Das, 2014; Kumar \& Vollmer, 2013). ${ }^{27-29}$

Children from Muslim community are more affected by diarrhoea as compared to other religious community (similar findings by Kamath et al., 2018; Mallick et al., 2020). ${ }^{12,14}$ Surprisingly mother's education (HS and above) has found to be positively linked with higher occurrence of diarrhoea. The possible explanation might be as mothers who are qualified and have knowledge about this disease, tends to recall and report more accurately. These findings are similar to other studies also. ${ }^{14,30}$ The incidence of occurrence is more among the children of working mother and similar findings are identified in some recent studies. ${ }^{21}$ Children of mothers within age group 25-34 years $(\mathrm{OR}=0.80$, $\mathrm{CI}=0.74,0.87)$ and $35-49$ years $(\mathrm{OR}=0.62, \mathrm{CI}=0.54,0.72)$ have shown less occurrence of childhood diarrhoea as compared to young mothers. Less experience of child rearing among younger mothers can be a plausible causal explanation. ${ }^{12,13,31-33}$

Rich household have less prevalence of diarrhoea against poor household. Similar findings were observed in few other national and international studies. $^{25,27,34-36}$ Age of the children is significantly associated with occurrence of children diarrhoea in this study. Children within age group $12-34$ months $(\mathrm{OR}=0.77, \mathrm{CI}=0.70,0.84)$ and more than 35 months (OR $=0.34, \mathrm{CI}=0.30,0.38$ ) have lesser occurrence of diarrhoea as compared to $0-12$ months children. This finding is relatable with the similar other studies. ${ }^{12,25,27,36,37}$

However, there were few limitations before considering profound study findings. This study has few assumptions on using Geographic Information System (GIS) tool. A Geographic Information System has been noted as an important technique in many aspects such as the rapid aggregation of multi-source big data, rapid visualization of epidemic information. Such efforts have provided solid region-specific spatial information support for decision-making, policy formulation, and effectiveness assessment of diarrhoea prevention and control. In the context of finding out the determinants, dietary diversity may play an 
Table 3

Estimated odds ratio obtained from logistic regression models of diarrhoea among 0-5 aged children in India, 2015-2016.

\begin{tabular}{|c|c|c|c|}
\hline \multirow[t]{2}{*}{ Predictors } & \multirow{2}{*}{$\frac{\text { Model-1 }}{\text { OR [95\% CI] }}$} & \multirow{2}{*}{$\frac{\text { Model-2 }}{\text { OR [95\% CI] }}$} & \multirow{2}{*}{$\frac{\text { Model-3 }}{\text { OR [95\% CI] }}$} \\
\hline & & & \\
\hline \multicolumn{4}{|l|}{$\begin{array}{l}\text { Environmental } \\
\text { variables }\end{array}$} \\
\hline \multicolumn{4}{|l|}{ Type of house } \\
\hline Kachcha & $1[1.00,1.00]$ & $1[1.00,1.00]$ & $1[1.00,1.00]$ \\
\hline Semi-Pucca & $\begin{array}{l}0.88 \\
{[0.75,1.04]}\end{array}$ & $\begin{array}{l}0.93 \\
{[0.62,1.38]}\end{array}$ & $\begin{array}{l}0.83 \\
{[0.54,1.26]}\end{array}$ \\
\hline Pacca & $\begin{array}{l}0.73 \\
{[0.62,0.86]^{* * *}}\end{array}$ & $\begin{array}{l}0.79 \\
{[0.53,1.18]}\end{array}$ & $0.8[0.53,1.22]$ \\
\hline \multicolumn{4}{|l|}{ Source of drinking Water } \\
\hline Improved & $1[1.00,1.00]$ & $1[1.00,1.00]$ & $1[1.00,1.00]$ \\
\hline Unimproved & $\begin{array}{l}0.83 \\
{[0.80,0.87]^{* * *}}\end{array}$ & $\begin{array}{l}0.79 \\
{[0.70,0.88]^{* * *}}\end{array}$ & $\begin{array}{l}0.84 \\
{[0.75,0.95]^{* *}}\end{array}$ \\
\hline \multicolumn{4}{|l|}{ Sanitation facility } \\
\hline Improved & $1[1.00,1.00]$ & $1[1.00,1.00]$ & $1[1.00,1.00]$ \\
\hline Unimproved & $\begin{array}{l}1.07 \\
{[1.04,1.10]^{* * *}}\end{array}$ & $\begin{array}{l}1.02 \\
{[0.93,1.11]}\end{array}$ & $\begin{array}{l}0.97 \\
{[0.87,1.07]}\end{array}$ \\
\hline \multicolumn{4}{|l|}{ Month of Interview } \\
\hline Rainy Session & $1[1.00,1.00]$ & $1[1.00,1.00]$ & $1[1.00,1.00]$ \\
\hline Others Session & $\begin{array}{l}1.05 \\
{[1.02,1.08]^{* * *}}\end{array}$ & $1[0.94,1.08]$ & $1[0.93,1.07]$ \\
\hline \multicolumn{4}{|l|}{$\begin{array}{l}\text { Socio-economic } \\
\text { variables }\end{array}$} \\
\hline \multicolumn{4}{|l|}{ Place of Residence } \\
\hline Urban & & $1[1.00,1.00]$ & $1[1.00,1.00]$ \\
\hline Rural & & $\begin{array}{l}1.04 \\
{[0.95,1.14]}\end{array}$ & $\begin{array}{l}1.01 \\
{[0.91,1.11]}\end{array}$ \\
\hline \multicolumn{4}{|l|}{ Social-group } \\
\hline $\begin{array}{l}\text { Scheduled Caste/ } \\
\text { Scheduled Tribe }\end{array}$ & & $1[1.00,1.00]$ & $1[1.00,1.00]$ \\
\hline Other Backward Class & & $\begin{array}{l}1.07 \\
{[0.99,1.17]}\end{array}$ & $\begin{array}{l}1.06 \\
{[0.98,1.16]}\end{array}$ \\
\hline Others & & $1[0.90,1.11]$ & $1[0.89,1.12]$ \\
\hline \multicolumn{4}{|l|}{ Religious group } \\
\hline Hindu & & $1[1.00,1.00]$ & $1[1.00,1.00]$ \\
\hline Muslim & & $\begin{array}{l}1.42 \\
{[1.28,1.56]^{* * *}}\end{array}$ & $\begin{array}{l}1.41 \\
{[1.27,1.56]^{* * * *}}\end{array}$ \\
\hline Others & & $\begin{array}{l}0.82 \\
{[0.72,0.93]^{* *}}\end{array}$ & $\begin{array}{l}1.16 \\
{[0.99,1.35]}\end{array}$ \\
\hline \multicolumn{4}{|l|}{ Mother's Education } \\
\hline No education & & $1[1.00,1.00]$ & $1[1.00,1.00]$ \\
\hline Primary & & $\begin{array}{l}1.05 \\
{[0.94,1.17]}\end{array}$ & $\begin{array}{l}1.07 \\
{[0.95,1.20]}\end{array}$ \\
\hline Secondary \& Higher & & $\begin{array}{l}1.06 \\
{[0.97,1.16]}\end{array}$ & $\begin{array}{l}1.12 \\
{[1.01,1.24]^{*}}\end{array}$ \\
\hline \multicolumn{4}{|l|}{ Mother's Occupation } \\
\hline Not Working & & $1[1.00,1.00]$ & $1[1.00,1.00]$ \\
\hline Working & & $\begin{array}{l}1.14 \\
{[1.05,1.24]^{* *}}\end{array}$ & $\begin{array}{l}1.21 \\
{[1.11,1.32]^{* * *}}\end{array}$ \\
\hline \multicolumn{4}{|l|}{ Mother's Age (In Years) } \\
\hline $15-24$ & & $1[1.00,1.00]$ & $1[1.00,1.00]$ \\
\hline $25-34$ & & $\begin{array}{l}0.80 \\
{[0.74,0.87] * * *}\end{array}$ & $\begin{array}{l}0.91 \\
{[0.83,0.99]^{*}}\end{array}$ \\
\hline $35-49$ & & $\begin{array}{l}0.62 \\
{[0.54,0.72]^{* * *}}\end{array}$ & $\begin{array}{l}0.77 \\
{[0.66,0.99]}\end{array}$ \\
\hline \multicolumn{4}{|l|}{ Wealth Index } \\
\hline Poor & & $1[1.00,1.00]$ & $1[1.00,1.00]$ \\
\hline Middle & & $\begin{array}{l}1.04 \\
{[0.94,1.15]}\end{array}$ & $\begin{array}{l}1.02 \\
{[0.91,1.13]}\end{array}$ \\
\hline Rich & & $0.9[0.80,1.01]$ & $\begin{array}{l}0.81 \\
{[0.71,0.93]^{* *}}\end{array}$ \\
\hline \multicolumn{4}{|l|}{ Child Variable } \\
\hline Male & & & $1[1.00,1.00]$ \\
\hline Female & & & $\begin{array}{l}0.87 \\
{[0.80,0.93]^{* * *}}\end{array}$ \\
\hline Age of Child (In Month & & & \\
\hline Less than 12 months & & & $1[1.00,1.00]$ \\
\hline $12-35$ months & & & $\begin{array}{l}0.77 \\
{[0.70,0.84] * * *}\end{array}$ \\
\hline More than 35 months & & & $\begin{array}{l}0.34 \\
{[0.30,0.38]^{* * *}}\end{array}$ \\
\hline
\end{tabular}

Table 3 (continued)

\begin{tabular}{|c|c|c|c|}
\hline \multirow[t]{2}{*}{ Predictors } & Model-1 & Model-2 & Model-3 \\
\hline & OR [95\% CI] & OR $[95 \% \mathrm{CI}]$ & OR [95\% CI] \\
\hline Having one child & & & $1[1.00,1.00]$ \\
\hline Having two children & & & $\begin{array}{l}1.03 \\
{[0.94,1.13]}\end{array}$ \\
\hline Having three and above & & & $\begin{array}{l}1.05 \\
{[0.94,1.16]}\end{array}$ \\
\hline Stunting & & & \\
\hline Normal & & & $1[1.00,1.00]$ \\
\hline Stunted & & & $\begin{array}{l}0.98 \\
{[0.90,1.05]}\end{array}$ \\
\hline Regions of India & & & \\
\hline North & & & $1[1.00,1.00]$ \\
\hline East & & & $\begin{array}{l}0.84 \\
{[0.74,0.95]^{* *}}\end{array}$ \\
\hline North East & & & $\begin{array}{l}0.53 \\
{[0.45,0.64]^{* * *}}\end{array}$ \\
\hline Central & & & $\begin{array}{l}1.29 \\
{[1.16,1.44]^{* * *}}\end{array}$ \\
\hline West & & & $0.9[0.77,1.05]$ \\
\hline South & & & $\begin{array}{l}0.65 \\
{[0.56,0.76] * * *}\end{array}$ \\
\hline Constant & 0.12 & 0.13 & 0.23 \\
\hline $\mathrm{N}$ & 234,104 & 38,346 & 35,002 \\
\hline $\mathrm{R} 2$ & 0.00 & 0.01 & 0.04 \\
\hline
\end{tabular}

$* \mathrm{p}<.10 ; * * \mathrm{p}<.05 ; * * * \mathrm{p}<.01$.

Diarrhoea: $0=$ not suffered from diarrhoea, $1=$ suffered from diarrhoea

important role, and hence, a further work may utilize information on this aspect while explaining the prevalence of diarrhoea. Similarly, immunisation status also can be used as an explanatory variable in further work. The responses of diarrhoea diseases information were completely based on mother's knowledge about the diarrhoea diseases which is not medically verified during the survey, hence, may not be true for generalizing overall study findings.

The present study does not only contribute in providing remarkable geographical variations in diarrhoea in India but also examines the contextual factors affecting the occurrence. Based on findings from the current study we recommend that the public health programmes must target to hot spot districts where the higher prevalence of diarrhoea is persisting and needful preventive measures should be taken to control the incident and intensity of childhood diarrhoea.

\section{References}

1 Parashar UD, Bresee JS, Gentsch JR, Glass RI. Rotavirus. Emerging infectious diseases. 1998 Oct;4(4):561. https://www.ncbi.nlm.nih.gov/pmc/articles/PMC2640254/pdf/ 9866732.pdf.

2 Yongsi HB. Pathogenic microorganisms associated with childhood diarrhea in Lowand-middle income countries: case study of Yaoundé-Cameroon. Int J Environ Res Publ Health. 2008 Dec;5(4):213-229. https://doi.org/10.3390/ijerph5040213.

3 WHO. Diarrhoeal disease: fact sheet. Available from: https://www who.int/news-roo $\mathrm{m}$ /fact-sheets/detail/diarrhoeal-disease; 2020, 15th Oct, 2020.

4 United Nations Children's Fund. Levels and Trends of Child Mortality: By United Nations Inter-agency Group for Child Mortality Estimation. 2019. UNICEF; 2019. Available from: https://www.unicef.org/media/60561/file/UN-IGME-child-mortalit y-report-2019.pdf.

5 WHO. Causes of child death. Available from: https://www.who.int/data/gho/ data/themes/topics/indicator-groups/indicator-group-details/GHO/causes-of-childdeath; 2017.

6 Walker CL, Rudan I, Liu L, et al. Global burden of childhood pneumonia and diarrhoea. Lancet. 2013 Apr 20;381(9875):1405-1416. https://doi.org/10.1016/ S0140-6736(13)60222-6.

7 Black RE, Cousens S, Johnson HL, et al. Global, regional, and national causes of child mortality in 2008: a systematic analysis. The lancet. 2010 Jun 5;375(9730): 1969-1987. https://www.who.int/immunization/monitoring surveillance/resou rces/Lancet_2010_withAppendix.pdf.

8 Anand K, Sundaram KR, Lobo J, Kapoor SK. Are diarrheal incidence and malnutrition related in under five children? A longitudinal study in an area of poor sanitary conditions. Indian Pediatr. 1994 Aug 1;31(8):943-948. https://europepmc.org/art icle/med/7883347.

9 Kammerer K, Higginson A, Hickey P. Recommendations for diarrhea management during medical stability operations. Mil Med. 2012 Jul 1;177(7):870-876. https:// doi.org/10.7205/MILMED-D-12-00032. 
10 Lakshminarayanan S, Jayalakshmy R. Diarrheal diseases among children in India: current scenario and future perspectives. J Nat Sci Biol Med. 2015 Jan;6(1):24. http s://www.ncbi.nlm.nih.gov/pmc/articles/PMC4367049/.

11 Chaikaew N, Tripathi NK, Souris M. Exploring spatial patterns and hotspots of diarrhea in Chiang Mai, Thailand. Int J Health Geogr. 2009 Dec;8(1), 1-0 http s://ij-healthgeographics.biomedcentral.com/track/pdf/10.1186/1476-072X-8-36. pdf.

12 Kamath A, Shetty K, Unnikrishnan B, Kaushik S, Rai SN. Prevalence, patterns, and predictors of diarrhea: a spatial-temporal comprehensive evaluation in India. BMC Publ Health. 2018 Dec;18(1). https://doi.org/10.1186/s12889-018-6213-z, 1-0.

13 Edwin P, Azage M. Geographical variations and factors associated with childhood diarrhea in Tanzania: a national population based survey 2015-16. Ethiopian journal of health sciences. 2019;29(4). https://doi.org/10.4314/ejhs.v29i4.13.

14 Mallick R, Mandal S, Chouhan P. Impact of sanitation and clean drinking water on the prevalence of diarrhea among the under-five children in India. Child Youth Ser Rev. 2020 Nov 1;118:105478. https://doi.org/10.1016/j.childyouth.2020.105478.

15 Njemanze PC, Anozie J, Ihenacho JO, Russell MJ, Uwaeziozi AB. Application of risk analysis and geographic information system technologies to the prevention of diarrheal diseases in Nigeria. Am J Trop Med Hyg. 1999 Sep 1;61(3):356-360. http ://www.chidicon.com/AJTMH.pdf.

16 Fang L, Yan L, Liang S, et al. Spatial analysis of hemorrhagic fever with renal syndrome in China. BMC Infect Dis. 2006 Dec;6(1):1-10. https://bmcinfectdis.biome dcentral.com/track/pdf/10.1186/1471-2334-6-77.pdf.

17 Sarkar R, Prabhakar AT, Manickam S, et al. Epidemiological investigation of an outbreak of acute diarrhoeal disease using geographic information systems. Trans $R$ Soc Trop Med Hyg. 2007 Jun 1;101(6):587-593. https://doi.org/10.1016/j. trstmh.2006.11.005.

18 Anselin L. Spatial Econometrics: Methods and Models. Springer Science \& Business Media; 2013 Mar 9.

19 Ghosh K, Dhillon P, Agrawal G. Prevalence and detecting spatial clustering of diabetes at the district level in India. J Public Health. 2020 Oct;28(5):535-545. https://doi.org/10.1007/s10389-019-01072-6.

20 Parvin F, Ali SA, Hashmi SN, Ahmad A. Spatial prediction and mapping of the COVID-19 hotspot in India using geostatistical technique. Spatial Information Research. 2021 Jan 4:1-6. https://doi.org/10.1007/s41324-020-00375-1.

21 Chattopadhyay A, Barnwal A. How far environmental factors are related with acute respiratory diseases and diarrhea among young children in India. Indian $J$ Matern Child Health. 2013;15(4). https://www.researchgate.net/profile/AshishAwasth i/publication/264899772_Comparison_of_mortality_trends_and_patterns_between_In dia_and_Japa n/links/53f5983c0cf2888a7491c40e/Comparison-of-mortality-tren ds-and-patterns-between-India-and-Japan.pdf.

22 Arnold BF, Colford Jr JM. Treating water with chlorine at point-of-use to improve water quality and reduce child diarrhea in developing countries: a systematic review and meta-analysis. Am J Trop Med Hyg. 2007 Feb 1;76(2):354-364. https://pdfs.se manticscholar.org/1477/ed7c4d14c0fe1aa7d2c088a9e27f18e5a6ce.pdf.

23 Cha S, Lee J, Seo D, et al. Effects of improved sanitation on diarrheal reduction for children under five in Idiofa, DR Congo: a cluster randomized trial. Infectious diseases of poverty. 2017 Dec;6(1):1-2. https://idpjournal.biomedcentral.com/track/pdf/10 .1186/s40249-017-0351-x.pdf.

24 Fink G, Günther I, Hill K. The effect of water and sanitation on child health: evidence from the demographic and health surveys 1986-2007. Int J Epidemiol. 2011 Oct 1;40 (5):1196-1204. https://doi.org/10.1093/ije/dyr102.

25 Fuller JA, Westphal JA, Kenney B, Eisenberg JN. The joint effects of water and sanitation on diarrhoeal disease: a multicountry analysis of the D emographic and $\mathrm{H}$ ealth S urveys. Trop Med Int Health. 2015 Mar;20(3):284-292. https://onlinelibrary. wiley.com/doi/pdfdirect/10.1111/tmi.12441.
26 Kuberan A, Singh AK, Kasav JB, et al. Water and sanitation hygiene knowledge, attitude, and practices among household members living in rural setting of India. J Nat Sci Biol Med. 2015;6(Suppl 1):S69-S74. https://www.ncbi.nlm.nih.gov/pmc /articles/PMC4630767/.

27 Nandi A, Megiddo I, Ashok A, Verma A, Laxminarayan R. Reduced burden of childhood diarrheal diseases through increased access to water and sanitation in India: a modeling analysis. Soc Sci Med. 2017 May 1;180:181-192. https://strath prints.strath.ac.uk/60117/1/nandi_etal_SSM_2016_Reduced_burden_of_childhood_ diarrheal diseases.pdf.

28 Kumar A, Das KC. Drinking water and sanitation facility in India and its linkages with diarrhoea among children under five: evidences from recent data. Int $J$ Humanit Soc Sci Invent. 2014 Apr;3(4):50-60. https://www.researchgate.net/profile/Ashwan i-Kumar 39/publication/315658105_Drinking_Water_and_Sanitation_Facility_in_Ind ia_and_Its_Linkages_with_Diarrhoea_among_Children_under_Five_Evidences_from_Re cent Data/links/58d902624585153378be32fb/Drinking-Water-and-Sanitation-Fa cility-in-India-and-Its-Linkages-with-Diarrhoea-among-Children-under-Five-Eviden ces-from-Recent-Data.pdf.

29 Kumar S, Vollmer S. Does access to improved sanitation reduce childhood diarrhea in rural India? Health Econ. 2013 Apr;22(4):410-427. https://doi.org/10.1002/ hec. 2809.

30 Ramanathan M, Vijayan B. Covariates of diarrhoea among under-five children in India: are they level dependent? PloS One. 2019 Aug 21;14(8), e0221200. https: doi.org/10.1371/journal.pone.0221200.

31 Yassin K. Morbidity and risk factors of diarrheal diseases among under-five children in rural Upper Egypt. J Trop Pediatr. 2000 Oct 1;46(5):282-287.

32 Boadi KO, Kuitunen M. Childhood diarrheal morbidity in the Accra Metropolitan Area, Ghana: socio-economic, environmental and behavioral risk determinants. J Health Popul Dev Ctries. 2005 Mar 15;7(1):15-22. https://www.researchgate.net/pr ofile/Markku-Kuitunen/publication/285705706 Childhood diarrheal morbidity i n the Accra_Metropolitan_Area_Ghana_Socio-economic environmental and behavi oral_risk_determinants/links/5698f72908ae748dfaff3092/Childhood-diarrheal-mor bidity-in-the-Accra-Metropolitan-Area-Ghana-Socio-economic-environmental-a nd-behavioral-risk-determinants.pdf.

33 Ghasemi AA, Talebian A, Masoudi Alavi N, Moosavi GA. Knowledge of mothers in management of diarrhea in under-five children, in kashan, Iran. Nurs midwifery stud. 2013;1(3):158-162.

34 Ezeh OK, Agho KE, Dibley MJ, Hall J, Page AN. The impact of water and sanitation on childhood mortality in Nigeria: evidence from demographic and health surveys, 2003-2013. Int J Environ Res Publ Health. 2014 Sep;11(9):9256-9272. https://doi. org/10.3390/ijerph110909256.

35 Gross R, Schell B, Molina MC, Leão MA, Strack U. The impact of improvement of water supply and sanitation facilities on diarrhea and intestinal parasites: a Brazilian experience with children in two low-income urban communities. Rev Saude Publica. 1989 Jun;23(3):214-220. https://doi.org/10.1590/S0034-89101989000300006.

36 Paul P, Mondal D. Maternal experience of intimate partner violence and its association with morbidity and mortality of children: evidence from India. PloS One. 2020 Apr 30;15(4), e0232454. https://doi.org/10.1371/journal.pone.0232454.

37 Mihrete TS, Alemie GA, Teferra AS. Determinants of childhood diarrhea among underfive children in Benishangul Gumuz regional state, north West Ethiopia. BMC Pediatr. 2014 Dec;14(1):1-9. https://link.springer.com/content/pdf/10.1186/1471 -2431-14-102.pdf.

38 Bhan MK. Accelerated progress to reduce under-5 mortality in India. The Lancet Global Health. 2013 Oct 1;1(4):e172-e173. https://doi.org/10.1016/S2214-109X (13)70076-7. 